\title{
Segmenting and Profiling Visitors to the Ulaanbaatar Naadam Festival by Motivation
}

\author{
Karen Thompson ${ }^{\mathrm{a},}$, , Peter Schofield ${ }^{\mathrm{b}}$ \\ ${ }^{a}$ Department of Marketing \\ University of Strathclyde \\ Glasgow GL4 0RQ, UK \\ Tel: +44 1415484801 \\ Fax: +44 1415522870 \\ karen.thompson@strath.ac.uk \\ ${ }^{b}$ Management and Management Sciences Research Institute \\ University of Salford \\ Salford M6 6PU, UK \\ Tel: +441612954579 \\ Fax: +44 1612952020 \\ p.schofield@salford.ac.uk
}

\begin{abstract}
The analysis of visitor motivation for attending festivals, as a basis for segmentation, is an important prerequisite for targeting markets, planning festival programmes and product positioning. This study identified five motivation dimensions for visitors attending the 2005 Naadam cultural festival in Mongolia, using factor analysis. A cluster analysis on the five factors produced five stable motivation segments: multipurpose seekers; indifferent; culture and sport seekers; togetherness, socialisation and sports seekers; and socialisation and local event seekers. Significant associations between motivation clusters and visitor age and type were identified, although there was no significant interaction between the clusters and visitor type with respect to overall satisfaction. The results are generally consistent with the outcomes of previous research on festival and event motivation in Europe and North America, suggesting universality of core themes. However, unique combinations of motivation dimensions suggests that further research is required to develop understanding of variable interaction.
\end{abstract}


Keywords: motivation, segmentation, factor-cluster analysis, cultural festival, Mongolia, Naadam 


\section{Introduction}

The success of a festival or event is heavily dependent on the implementation of a strategic marketing plan; an understanding of the relationship between a destination event and its visitors and the identification of target markets are critical factors in this process. Within this framework, market segmentation is extensively used to understand the characteristics of visitors and identify distinct groups that might require separate experiences and marketing service mixes. However, the use of inappropriate segmentation techniques can result in destinations either missing strategic marketing opportunities or failing to reap the rewards of a tactical marketing campaign (Bloom, 2004). The analysis of visitor motivations for attending festivals as a basis for segmentation is an important prerequisite for targeting visitor markets, planning festival programmes and their positioning (Crompton \& McKay, 1997). Moreover, the segmentation of markets based on visitor motivations facilitates both the identification of the strengths and opportunities of each market and their satisfaction (Lee \& Lee, 2001). 


\section{Dimensions of Festival and Event Motivation}

Since Uysal et al. (1993) conducted their groundbreaking study of the dimensions of event motivation, increasing attention has been paid in the literature to testing and refining the underlying motivations which influence attendance at festivals and events. Lee et al. (2004) conducted an extensive literature review in this area, and it is considered more useful here to present an updated summary of their review (presented below as Table 1) than to repeat their efforts. As Table 1 illustrates, a number of salient dimensions of motivation have been identified by a range of studies undertaken in a variety of festival settings, across a number of cultural groups and often using different scale items to measure the concept of festival motivation. Some of the dimensions appear to be specific to the event, its setting or the nature of the attendees. Other dimensions of motivation occur repeatedly across the various studies and will therefore be explored in more detail below.

The desire to 'escape' and 'recover equilibrium' has been identified by a number of reports on festival motivation. Uysal et al. (1993), in one of the first studies in this area, found escape to be one of five factors, extracted from 24 motivational items, explaining motivation to attend the South Carolina Corn Festival in the USA. No significant between groups differences were found on this factor across the demographic variables within the sample. Later studies by Mohr et al. (1993), Scott (1996), Schneider \& Backman (1996), Lee (2000) and Lee et al. (2004) identified a similar escape factor among festival attendees in the USA, Jordan and South Korea. Backman et al. (1995) identified a factor which they labelled 'relaxation' and which is comprised of two items concerned with rest and relaxation and getting away from pressures and responsibilities. This factor thus exhibits strong similarities with the 'escape' dimension. Of the above studies, 
Scott (1996) found statistically significant differences on scores for this factor between the three different festivals populations which he surveyed, indicative of differences in the overall composition of motivation at different festivals. Backman et al. (1995) established a significant difference between age groups on their relaxation factor. Meanwhile, Lee (2000) failed to establish a significant difference between domestic and foreign visitors on the escape factor, but did identify differences between Eastern (Korean and Japanese) and Western (American and European) national groupings.

The novelty of the event was found to be one of the five delineated dimensions in the original exploratory study of event motivation by Uysal et al. (1993) and, in common with the escape factor, exhibits similarities with one of Crompton's (1979) socio-psychological motives. The novelty pull of the event has since been identified as an underlying factor by all but three of the subsequent studies summarised in Table 1, namely Backman et al. (1995), Scott (1996) and Schneider \& Backman (1996). Nonetheless, similar factors arguably exist within the above factor solutions. For example, Scott (1996) identified a curiosity factor on which he found statistically significant differences for first time and repeat visitors. Crompton (1979) indicated that curiosity appeared as a synonym for novelty in his work on pleasure travel motivation, citing an associated preference for going to previously unvisited destinations. Indeed, there appears to be some disparity between the novelty and excitement factors reported in later studies with the ‘site novelty’ factor reported by Formica \& Uysal (1998) expressing first time visitation, as opposed to the desire for adventure and excitement and to satisfy curiosity which contribute to Lee's (2000) novelty factor. Moreover, examination of Table 1 reveals that, whilst the early studies of festival and event visitors identified delineated excitement as one of the salient factors underpinning motivation, the most recent studies (Lee 2000; Lee et al. 2004; Chang, 2005) failed 
to confirm this factor. Attributes expressing excitement in these latter two studies loaded respectively on the factors novelty and festival participation and learning. The authors do not attempt to account for this difference in the factor structures.

The socialization factor appears in all of the studies reviewed in Table 1. Crompton (1979) argues that trip motivation can be people rather than place oriented and this dimension of motivation appears to be particularly important in the case of festivals and events. Socialization refers to the desire and willingness to meet with people from beyond the normal circle of acquaintance and to extend social contacts. Given the nature of festivals as places where a large number of people with a common interest are gathered together, it is not surprising that socialization has repeatedly been shown to be a salient factor in event motivation. It should also be noted that in some studies (Crompton \& Mackay, 1997; Lee, 2000) a distinction has been established between the desire to spend time with friends and associates (known-group socialization) and the appeal of meeting new people or observing others (external interaction/socialization). Crompton \& Mackay (1997) also reported a gregariousness factor, which they believed to be closely associated to the latter two socialization factors. Furthermore, Formica \& Uysal (1996) found statistical evidence, in the case of the Umbria Jazz Festival in Italy, that residents attending the festival were more strongly motivated by the socialization factor than non-residents.

The importance of being together as a family has emerged from the majority of studies into event motivation as a salient dimension, normally labelled family togetherness. Crompton \& Mackay (1997) were surprised not to identify a factor, which represented Crompton's (1979) domain of enhancing kinship relations and ultimately concluded that their research instrument should be 
extended to incorporate this factor. It is notable that the only other study, of those reviewed in Table 1, which failed to identify the family togetherness factor (Chang, 2005) based the survey instrument on that used by Crompton \& Mackay (1997). In the other studies family togetherness has been found to represent an important motivational factor although, unsurprisingly, its importance has been found to differ according to matrimonial status (Uysal et al., 1993; Backman et al., 1995).

The influence of exploring new cultures on motivation to attend festivals and events emerges strongly as the factor explaining the highest percentage of the variance in some of the more recent studies (Crompton \& Mackay, 1997; Lee, 2000; Lee et al. 2004) and as a lesser factor in others (Formica \& Uysal, 1996; 1998; Chang, 2005). The importance of culture in motivation to visit an event is clearly linked to the significance and interest of the culture(s) being celebrated by any individual event. It is therefore not surprising that this factor should emerge unambiguously in studies of motivation to attend the World Cultural Expo (Lee, 2000; Lee et al. 2004). It is hypothesised, and will be argued below, that one of the key attractions of the Naadam Festival is the traditional and unique culture that can be consumed there.

\section{[See Table 1]}

In summary, the studies discussed above broadly exhibit similar factor solutions across different events in a range of geographical and cultural settings, suggesting that there are a set of key factors (as identified above) that explain the motivation behind attendance at festivals and events. Moreover, statistical evidence has been found to suggest that some significant motivational differences exist between geographic market segments (Formica \& Uysal, 1996; Lee, 2000; Lee 
et al., 2004) and demographic groups (Uysal et al., 1993; Backman et al. 1995) for the case of some cultural festivals. It should be stressed that the lack of differences found between the underlying dimensions of motivation across different festivals may, in part, be due to flexible interpretation of the factors, with many motivation items appearing within different factors in different authors' solutions. Indeed it is worth reiterating that Scott's (1996) research found differences between motivations sought for different festivals within the same study. In a similarly constructed experiment, however, Crompton \& Mackay (1997) found that the same factor structures existed across different events within the same festival, but that some of the factors applied more to some events than others. The research documented below therefore aimed to respond to Lee's (2004) call for further exploration of differences between motivation clusters on the basis of demographic and behavioural variables, in light of the increasing internationalisation of events. 


\section{Naadam Festival: Attraction and Motivation}

Eriin Gurvan Naadam (The Festival of the Three Manly Sports) is an annual sporting and cultural festival, more accurately a series of annual festivals, held throughout Mongolia. The event has survived in its traditional form for more than two centuries. The origin of the festival is traced to the skills of war, defense and hunting (Kabzińska-Stawarz, 1991), and traditionally celebrates the prowess of the male, but is also linked to folk-religious rites celebrating and giving thanks for health and wealth and prosperity (Pegg, 2001). During the period of Soviet occupation, Naadam was sponsored by the Mongolian government. The Naadam Festival is the most important sporting event in the Mongolian calendar, celebrating the three traditional games of men, wresting, horseracing and archery. Minor festivals are held in every province and county, with the largest event held in the capital, Ulaanbaatar on $11^{\text {th }}$ and $12^{\text {th }} \mathrm{July}$. The festival attracts a large audience across these two days to the National Stadium, on the outskirts of the city. Since the date of the festival coincides with the anniversary of the foundation of the state of Mongolia, the event takes place during an annual holiday.

The calibre of the sporting events, and in particular the wrestling, attracts a sizeable audience to observe the best competitors from all over the country. There is an enormous amount of prestige attached to winning the sports competitions; the champion wrestler is regarded as a national hero. However, the traditions underlying these sports are arguably equally important in attracting visitors to Naadam. The sportsmen and women compete in traditional costume and there is an air of theatre surrounding the sporting events. Wrestlers, for example, are escorted by heralds who sing of their sporting talents before each bout takes place. Similarly, there are important traditions attached to the horseracing events. At the finishing line of these races across the 
Steppe, spectators crowd close to the competitors to bath in the dust and sweat of the winning horses. Traditional victory songs are sung to the horses and libation rituals are undertaken. The opportunity to observe and participate in these historic, indigenous traditions clearly holds appeal for tourists from overseas, but is also argued to be a valuable way of reaffirming Mongolian identity and culture for the native audience, some of whom travel great distances to attend.

A further strong motivation for Mongolians in visiting the Naadam festival is the opportunity of spending time with family and friends. It is worth noting that, prior to collectivisation, Naadam celebrations presented one of the few opportunities for nomadic herders to assemble together, renewing old and making new acquaintances. In present day Mongolia, almost one third of the population lives in the capital city and there are a large number of Mongolian nationals living outside Mongolia. The Naadam holiday is a traditional time for families to meet.

In identifying motives for attending Naadam, it is useful to stress that the Tourist experience of Naadam may be a very different one to that of Mongolian people. In the first instance, a considerable percentage of the international visitors to the Naadam Festival attend as part of an organised package tour. Because these tours have a tightly scheduled itinerary, tourists typically attend the opening ceremony on the first day, staying only to watch the first half hour or first round of the wrestling. They are then taken for lunch by the tour operator and, in the afternoon, may visit the horseracing, which is about thirty kilometres outside the city. Independent travellers and local people, on the other hand, are more likely to spend a full day at the stadium, watching the various sports competitions that are taking place as well as eating, drinking, shopping and socialising at stalls which are located outside the stadium. 
It was hypothesised that the key domains of motivation for attending the Naadam Festival would broadly encompass the key factors identified in the literature review above. Cultural exploration applies both in the sense of international visitors wishing to observe Mongolian culture and local people wishing to learn more about their own culture. Socialization is thought to be an important motivator for the independent traveller who wishes to meet and enjoy the event with like-minded people, and indeed the package tourist may be motivated by the experience of visiting the festival in a group. The novelty and escape factors could be argued to apply not only to the Naadam Festival but, for international visitors, also to Mongolia as a destination. In addition, though, with regard to the characteristics of the event, it is useful to embrace the probable importance of the sports events in motivation to attend Naadam. There is a growing body of literature investigating underlying motives for attending sports festivals. In particular, investigations by Kim \& Chalip (2004) shed some light on motivations for attending sports events which are associated with fan interest (identifying with a team or particular competitors) and aesthetic appreciation of the sport. This motivation factor is hypothesised to be of greater importance for Mongolians attending Naadam than for international visitors who have little understanding of the sport events included in the festival.

Within this context, there are four objectives.

1. Identify the underlying dimensions of motivation for visitors attending the 2005 Naadam Festival.

2. Segment the Naadam festival market on the basis of the motivation factors.

3. Assess the differences between domestic and international visitors with respect to the motivation clusters. 
4. Examine the influence of motivation clusters and type of visitors (domestic and international) on levels of overall satisfaction. 


\section{Methodology}

\subsection{Instrumentation}

A three page self-complete questionnaire was designed to survey visitors to the two day Naadam Festival in Ulaanbaatar, Mongolia in July 2005. The instrument contained a scale of 27 items measuring motivation for attending the Naadam Festival; this was generated following a review of the literature on cultural festival and event motivation and motivation for attending sporting events. The 27 items ultimately selected were hypothesised to be the most appropriate for the Naadam festival, given its dual role as a cultural and sporting festival. Subjects were asked to rate their level of agreement/ disagreement with each statement relating to their visit motivation presented on 7-point Likert-type scales ranging from 'Very Strongly Disagree' (1) to 'Very Strongly Agree' (7) with a no response option; each option was clearly labelled and numbered (Orams \& Page, 2000). In addition to the motivation statements, other sections of the questionnaire asked respondents about the characteristics of their stay, their levels of satisfaction with certain aspects of the Naadam Festival, overall satisfaction with the festival and likelihood of revisiting. The final section of the instrument collected socio-demographic information on respondents.

A test of face validity was conducted by asking a number of local experts to comment on the suitability of the items. Some of these experts were tour operators, others were connected with the organisation of the festival. As a result of this exercise, some small changes were made, in particular to the items relating to the sporting events. A number of the experts recommended breaking down the satisfaction items to measure the contribution of individual sporting events, rather than their contribution as a whole. The questionnaire was then translated into Mongolian 
by a native speaker. As a further test of reliability, a back-translation was conducted by a different native speaker, who had not had access to the original English language questionnaire. Some slight differences necessarily existed between the Mongolian language questionnaire and the questionnaire for international visitors with regard to trip characteristics. For example, Mongolian visitors were asked whether or not they lived in Ulaanbaatar and, if not, requested to provide details of their stay in the capital, whereas overseas visitors were asked both about their trip to Mongolia and their stay in Ulanbaatar. Furthermore, an additional motivation item was included in the questionnaire for overseas visitors, measuring the inclusion of Naadam as part of an organised tour package in their decision to visit the festival.

\subsection{Sampling Design}

An on-site survey was undertaken in July 2005 at a number of sites across the festival including inside the main Naadam stadium, the wrestling stadium, the horse racing venue and outside the stadium in the area of the stalls and other entertainments. International visitors were targeted by researchers with English as their first language and with a number of other language skills. Whilst many of the overseas visitors spoke good enough English to respond to questions, researchers were able to assist Spanish, French, German and Russian speakers with any linguistic difficulties. Some non-responses were inevitably experienced due to language difficulties, particularly in the case of the Japanese market. A team of Mongolian speaking researchers was recruited from the tourism department of Orkhon University in Ulaanbaatar and trained in the necessary interview skills through an interpreter. Although designed to be self-complete, in the event subjects were interviewed and questionnaires completed on the spot by the research team. A convenience sample of visitors produced 539 useable questionnaires; 182 (33.8\%) were completed by international visitors and 357 (66.2\%) by Mongolian nationals. The sample 
contains $45 \%$ females / 55\% males and the breakdown of age categories is as follows: $65+$ (1.7\%), 55-64 (6.7\%), 45-54 (15.8\%), 35-44 (21.3\%), 25-34 (30.9\%) and 18-24 (23.6\%).

\subsection{Data Analysis}

The data were analysed using SPSS Version 13.0. A factor analysis, using principal components as the method of extraction, with oblique rotation was conducted on the subjects' ratings on the motivation scale items to delineate underlying dimensions. All factors with eigenvalues greater than or equal to 1.0 were retained, because they were considered significant (Kaiser 1974). The determinant of the correlation matrix, Cronbach's alpha coefficient, a Kaiser-Meyer-Olkin (KMO) test of sampling adequacy and Bartlett's test of sphericity confirmed the factorability of the correlation matrix. A reliability coefficient (Cronbach's alpha) was computed for each factor to estimate the reliability of each scale; all factors with a reliability coefficient above 6.0 were considered to be acceptable for an exploratory study (Churchill, 1979). Hierarchical and nonhierarchical cluster analyses were used to identify meaningful motivation segments from the factors. Independent samples $t$-tests and ANOVA were employed to determine the characteristics of cluster profiles and validate the outcomes. 


\section{Results}

\subsection{Dimensions of Visitor Motivation}

Subjects' ratings on the motivation attributes were subjected to factor analysis to identify underlying dimensions. Table 2 presents the results; one attribute, 'the Naadam festival was part of an organised tour' was excluded because of its low correlation with other attributes in the construct. The 26 remaining Naadam festival items were analysed using principal components as the method of extraction with an oblique rotation because the extracted factors were correlated (Pedhazur \& Schmelkin, 1991). The minimum coefficient for factor items to be included in the final scale was .40, as recommended by Stevens (1992) for the sample size. The Kaiser-MeyerOlkin (KMO) measure of sampling adequacy (.90) was 'meritorious' (Kaiser 1974) and the Bartlett's Test of Sphericity reached statistical significance $\left(X^{2}(325)=4305.39 ; p<.001\right)$, supporting the factorability of the correlation matrix.

\section{[Refer to Table 2]}

The five-factor solution (with eigenvalues $>1.0$ ) accounted for $55.27 \%$ of the overall variance before rotation (Table 2). Factor 1 (.82 alpha) accounts for $29.83 \%$ of the variance and loads mainly on the motivational attributes describing cultural exploration and has been labelled as such. This demonstrates the relative importance of the cultural motivation. Factor 2 (.79 alpha) accounts for $11.33 \%$ of the variance in the data and loads on variables that seem to describe togetherness (with family and friends). Factor 3 (.64 alpha) accounts for $5.53 \%$ of the variance and loads on the attributes describing socialisation. Factor four (.72 alpha) accounts for $4.59 \%$ of the variance and has been labelled sports attraction because of its variable loadings. Factor 5 
(.77 alpha) accounts for $3.99 \%$ of the variance and appears to describe local special events. The factor solution was clean. Communalities range from 0.356 to 0.689 (please refer to Table 2).

The motivation dimensions that emerged from the factor analysis are generally consistent with the results from earlier festival and event motivation studies (Uysal et al., 1993; Mohr et al., 1993; Backman et al., 1995; Schneider \& Backman, 1996; Scott et al., 1996; Formica \& Uysal, 1996, 1998; Crompton \& Mackay, 1997; Lee, 2000; Lee et al., 2004; Chang, 2005). This supports the notion of universality in the range and grouping of event motives (Lee et al., 2004).

\subsection{Motivation Clusters}

To develop further our understanding of the motivation dimensions, a cluster analysis was performed on the five factors. Initially, a hierarchical cluster analysis was used to identify the number of clusters required for a K-means non-hierarchical algorithm (Hair et al., 1998). Five distinct clusters emerged from this analysis. Initial cluster centres were selected by SPSS Version 13.0 and iterated until the Euclidean distance between centroids changed less than $2 \%$ to reduce the bias of designating initial cluster seeds and produce stable clusters when the criterion had been met. The 'average linkage between groups' (unweighted pair-group using arithmetic means) method of clustering was used.

Table 3 shows the results from a one-way ANOVA test to show that all five factors contribute to differentiating the five motivation clusters $(p<.001)$. Additionally, the results from the multiple range tests using the Scheffe procedure show that in the large majority of cases there are significant differences between clusters with respect to each dimension. Exceptions are clusters I 
and III on cultural exploration, clusters II and V and III and IV on togetherness, clusters II and III on socialisation and clusters IV and V on sports attraction. The clusters are also significantly differentiated with respect to their levels of overall satisfaction $(p<.001)$. Overall, the significant differentiation supports the K-means cluster analysis outcome presented in Table 4.

\section{[Refer to Table 3]}

\section{[Refer to Table 4]}

Cluster I: Multi-purpose seekers. This cluster contains 156 visitors (28.9\%) - the second largest segment. This cluster has the highest mean score on all five dimensions and as such, it was labelled 'multi-purpose seekers'.

Cluster II: Indifferent. This cluster contains only 38 visitors $(7.1 \%)$ - the smallest of the five. It has the lowest mean scores on all dimensions with the exception of 'togetherness', where it has the second to lowest mean score (3.70). It has therefore been labelled 'indifferent'.

Cluster III: Culture and Sports Seekers. This cluster contains 81 visitors (15.0\%). It has the second highest mean scores on 'cultural exploration' (6.29), 'sports attraction' (6.02) and 'togetherness' (5.81). The cluster has therefore been labelled 'culture and sport seekers'.

Cluster IV: Togetherness, Socialisation and Sports Seekers. This cluster contains 167 visitors $(30.9 \%)$ - the largest segment. It has the third largest mean ratings for 'togetherness' (5.10), 'socialisation' (4.99) and 'sports attraction' (4.97) and has been labelled accordingly. 
Cluster V: Socialisation and Local Special Event Seekers. This cluster has 97 visitors (18\%). It contains the second highest mean scores for 'socialisation' (5.95) and 'special events' (5.74). It has been labelled 'socialisation and local special event seekers'.

The clusters that have been identified are generally similar to those which emerged from previous motivation research on festivals and events, notwithstanding the subjective interpretation of factor loadings both here and previously. A 'multi-purpose seekers' cluster was found by Lee et al. (2004) and whilst 'culture and sport seekers' is new and clearly relates to the main activity at the Naadam Festival, culture has featured predominantly in clusters identified in previous research (Formica \& Uysal, 1996; Crompton \& Mackay, 1997; Lee, 2000; Lee et al., 2004; Chang, 2005). Cluster IV links togetherness and socialisation with sport. Again, the nature of the event is likely to have influenced the particular combination of factors. Togetherness and socialisation are common motivational factors which have defined clusters in previous research (Uysal et al., 1993; Mohr et al., 1993; Scott et al., 1996; Backman et al., 1995; Schneider \& Backman, 1996; Crompton \& Mackay, 1997; Formica \& Uysal, 1998; Lee, 2000; Lee et al., 2004; Chang 2005). It should be noted that in previous research togetherness is linked to family activity whereas, here it is associated with both friends and family. Cluster V links socialisation with local special events. It is difficult to determine whether 'local' or 'special' (or both) are key motivational characteristics of this cluster. If the latter is key then this may also support earlier findings with respect to 'novelty' being an important motivating factor (Uysal et al., 1993; Mohr et al., 1993; Formica \& Uysal, 1996; Lee, 2000; Lee et al., 2004; Chang 2005).

Overall, the cultural exploration dimension (factor 1) has the highest mean scores for all of the clusters with the exception of Cluster $\mathrm{V}$ and has the highest aggregated mean score (5.48) for all 
clusters. This supports the factor analysis finding that the cultural motivation was the most important of the five dimensions. As expected, the findings indicate the complexity of the cluster solution in that festival visit motivations are shared among clusters. For example, clusters I, III and IV have a sports interest in common while clusters I, IV and V share socialisation as a motivating factor. They are however differentiated from each other because these shared elements are combined with other factors to create distinctive motivation-based segments.

The 'multi-purpose seekers' (cluster I) emerged as the most distinctive market segment with respect to their highest mean ratings on all factors; they also have the joint second highest mean rating for overall satisfaction (5.82). Lee et al (2004) also found this segment to be the most important. The 'culture and sports seekers' (cluster III) have the highest mean score for overall satisfaction (6.09). This outcome suggests that festival marketers should target these segments, particularly the multi-purpose seekers, to achieve positive recommendations and repeat visitation.

\subsection{Validation of Cluster Solution}

As a validity check for the stability of the cluster solution, a second K-means cluster analysis was performed, allowing the procedure to randomly select the initial cluster seed points (Hair et al., 1998). Four clusters were produced. All five factors contribute to differentiating the four motivation clusters (Table 5) and, with the exception of three cases, there are significant differences between clusters with respect to each dimension. The four clusters are also significantly differentiated with respect to their levels of overall satisfaction. Whilst four clusters were produced (Table 6), the results are consistent in that the cluster characteristics are comparable; this confirms that motivation cluster differences are valid. Additionally, both the 
five and four cluster solutions depict groups that have predictive validity because all clusters are significantly differentiated $(\mathrm{p}<.001)$ on the basis of overall satisfaction (Tables 3 and 5).

\subsection{Motivation Cluster Profiles}

The profile for the five motivation clusters is given in Table 7. Statistically significant associations were identified between motivation clusters and visitor type (domestic and international) and visitor age. Within the international visitor segment, nationalities were not represented in sufficient quantities to allow disaggregation. A comparison of domestic and international festival visitors' motivation cluster profiles shows that the majority of domestic visitors can be categorised as 'togetherness, socialisation and sports seekers' $(36.41 \%)$,

\section{[Refer to Table 5]}

\section{[Refer to Table 6]}

'multi-purpose seekers' (32.49\%) and 'culture and sports seekers' (22.13\%). By comparison, international visitors are predominantly 'socialisation and local special event seekers (51.10\%), with most of the balance comprising either 'multi-purpose seekers $(21.98 \%)$ or 'togetherness, socialisation and sport seekers' $(20.33 \%)$. It is interesting to note that while multi-purpose seekers' and 'togetherness, socialisation and sport seekers' are found in both domestic and international visitor segments, the two visitor types are distinguished from each other on the basis that domestic visitors are 'culture and sport seekers' whilst international visitors are 'socialisation and local special event seekers'.

\section{[Refer to Table 7]}


The motivation cluster visitor profiles subdivided by visitor type (domestic and international) are given in Table 8. A significant association between gender and motivation cluster membership is evident among domestic participants, but not for international visitors. No other significant associations were identified. Domestic segmented clusters therefore appear to be similar to international clusters on the basis of the demographic variables and their experience with respect to their overall satisfaction with the festival. A t-test for differences between domestic and international visitor satisfaction levels confirmed this result $[t(517)=1.82, \mathrm{p}=.07]$. The results support the findings of Lee et al. (2004) who also found similarities between domestic and international festival motivation clusters with respect to age and gender.

\section{[Refer to Table 8]}

\subsection{The Influence of Cluster and Visitor Type on Visitor Satisfaction}

A two-way ANOVA test was used to examine the influence of the five motivation clusters and type of visitors (domestic and international) on visitor satisfaction (Table 9). Levene's test confirmed that the homogeneity of variance assumption had not been violated (.47). The results show that there was a significant main effect on overall satisfaction level between the five clusters $[F(4,509)=16.42, \mathrm{p}<.001]$. This supports the results presented above. Post-hoc tests showed significant differences $(p<.001)$ between all clusters with the exception of II (indifferent) and IV (togetherness, socialisation and sports seekers) and III (culture and sports seekers) and V (socialisation and local special event seekers).

\section{[Refer to Table 9]}


By comparison, there was no significant main effect on overall satisfaction level between type of visitors $[F(1,509)=.46, \mathrm{p}=.50]$. Additionally, there is no significant interaction between the five clusters and visitor type with respect to overall satisfaction level $[F(1,509)=$ $.79, \mathrm{p}=.53]$, i.e. the type of visitor did not act as an interaction variable for the effect of motivation on overall satisfaction. This result may be attributed to the undifferentiated satisfaction level between domestic and international visitors in each cluster and overall (Table $10)$.

\section{[Refer to Table 10]}




\section{Conclusions}

Festivals and events have the potential to improve a destination's image, contribute to the local and regional economy and enhance pride and culture provided that they are planned and managed effectively. A key consideration is the relationship between the event or festival and the visitor with regard to identifying consumer needs, planning activities and amenities and effectively positioning the product by communicating relevant benefits to particular target markets. Analysis of visitor motivation is a critical success factor in this process.

This study identified five motivation dimensions for visitors attending the 2005 Naadam cultural festival in Mongolia, using factor analysis: cultural exploration, togetherness (with family and friends), socialisation, sports attraction and local special events. The first dimension, cultural exploration, explained the largest proportion of total variance, reaffirming that culture was a central theme of the festival. Overall, the dimensions were generally consistent with those identified in previous research on festival and event motivation in Europe and North America. This suggests that these core themes are universal and should underpin production and marketing models used to plan and manage all festivals and events, although the unique combinations of motivation dimensions identified in this study also suggests that further research is needed to develop our understanding of the influence of both destination and festival 'pull' factors.

A cluster analysis was performed on the five factors and five statistically differentiated motivation segments were identified: 'multipurpose seekers'; 'indifferent'; 'culture and sport seekers'; 'togetherness, socialisation and sports seekers'; and 'socialisation and local event seekers'. The stability of the cluster solution was validated through a comparison with a four- 
cluster outcome, which demonstrated its similarity; the predictive validity of the five clusters was also established through their differentiation on the basis of overall satisfaction. Additionally, the cluster characteristics generally support the outcomes from previous research suggesting that a core set of motives for participation in festivals and events exists. The 'multi-purpose seekers' emerged as the most distinctive market segment with respect to their highest mean ratings on all factors and the joint second highest mean rating for overall satisfaction; together with the "culture and sports seekers', who recorded the highest mean score for overall satisfaction, the 'multipurpose seekers' should be targeted by festival marketers to maximise positive word-of-mouth recommendations and repeat visitation.

Cluster profiles were established using demographic and behavioural characteristics. Significant associations between motivation clusters and visitor age and type were identified with 'culture and sport' and 'socialisation and local special event' cluster membership being the key distinguishing motivation features of domestic and international segments, respectively. There was, however, no significant interaction between the five clusters and visitor type with respect to overall satisfaction. Although cultural differences were not pronounced on the evaluative measures of the event, some differences were established with regard to the motivation dimensions. For Mongolians, the importance of culture and sport mirrors the significance of the Naadam festival as a symbol of their national identity and a celebration of their indigenous culture. For international visitors, the identification of 'socialisation' and 'local special events' as key motivation dimensions should facilitate the development of more targeted festival planning and promotion for this increasingly important segment; both cultural and economic agendas must be considered. 
The outcomes from the study should be considered in relation to its limitations. The survey represents a cross sectional perspective on visitors attending the 2005 Naadam Festival in Mongolia. Further motivation research on events and festivals in this country should be carried out to test the reliability of the findings. This research should examine a wide range of variables including first time and repeat visitor representation, previous event visitation profiles, visitor attitudes and behavioural characteristics, activity/experience time-budget information and overall measures of recommendation and repeat visitation. Further research in a range of international locations is also required to both test the concept of a core set of motives and examine their relationship with other variables (e.g. nationality and cultural background) to facilitate the further development of visitor profiling. 


\section{References}

Backman, K.F., Backman, S.J., Uysal, M., \& Sunshine, K. M. (1995). Event tourism: An examination of motivations and activities. Festival Management and Event Tourism, 3(1), $15-24$.

Bloom, J.Z. (2004). Tourist market segmentation with linear and non-linear techniques. Tourism Management, 25, 723-733.

Chang, J. (2005). Segmenting tourists to aboriginal cultural festivals: An example in the Rukai tribal area, Taiwan. Tourism Management, (in press).

Churchill, G. A. (1979). A Paradigm for Developing Better Measures of Marketing Constructs. Journal of Marketing Research, 16 (February), 64-73.

Churchill, G.A. (1991). Marketing Research: Methodological Foundations. Chicago: Dryden Press.

Crompton, J. (1979). Motivations for Pleasure Vacation. Annals of Tourism Research, 6(4), 408-424.

Crompton, J.L., \& McKay, S.L. (1997). Motives of visitors attending festival events. Annals of Tourism Research, 24(2), 425-439.

Formica, S., \& Uysal, M. (1996). A market segmentation of festival visitors: Umbria Jazz festival in Italy. Festival Management and Event Tourism, 3(4), 175-182.

Formica, S., \& Uysal, M. (1998). Market segmentation of an international cultural-historical event in Italy. Journal of Travel Research, 36(4), 16-24.

Hair, J.F., Anderson, R.E., Tatham, R.L. \& Black, W.C. (1998). Multivariate Data Analysis. ( $5^{\text {th }}$ ed.). Upper Saddle River, NJ.: Prentice Hall. 
Kabzińska-Stawartz, I. (1991). Games of Mongolian Shepherds. Warsaw: Polish Academy of Sciences.

Kaiser, H.F. (1974). An index of factorial simplicity. Psychometrika, 39, 31-36.

Kim, N-Wann, D.L., Melnick, M.J., Russell, G.W. \& Pease, D.G. (2001). Sport fans:

The psychology and social impact of spectators. New York: Routledge.

Lee, C. K. (2000). A comparative study of Caucasian and Asian visitors to a Cultural Expo in an Asian setting. Tourism Management, 21(2), 169-176.

Lee, C.K. \& Lee, T.H. (2001). World Culture EXPO segment characteristics. Annals of Tourism Research, 28 (3), 812-816.

Lee, C.K., Lee, Y.K. \& Wicks, B.E. (2004). Segmentation of festival motivation by nationality and satisfaction. Tourism Management, 25 (1), 61-70.

Long, P.T. \& Perdue, R.R. (1990). The economic impact of rural festivals and special events: Assessing the special distribution of expenditures. Journal of Travel Research, 28 (4), 10-14. Mohr, K., Backman, K. F., Gahan, L. W., \& Backman, S. J. (1993). An investigation of festival motivations and event satisfaction by visitor type. Festival Management and Event Tourism, 1(3), 89-97.

Orams, M.B. \& Page, S.L. (2000). Designing self-reply questionnaires to survey tourists: issues and guidelines for researchers. Anatolia, 11 (2), 125-139.

Pedhazur, E. \& Schmelkin, L. (1991). Measurement, Design and Analysis. Hillsdale, New Jersey: Erlbaum.

Pegg, C. (2001). Mongolian Music, Dance and Oral Narrative: Performing Diverse Identities, Seattle: University of Washington Press.

Schneider, I.E., \& Backman, S. J. (1996). Cross-cultural equivalence of festival motivations: A study in Jordan. Festival Management and Event Tourism, 4(3/4), 139-144. 
Scott, D. (1996). A comparison of visitors' motivations to attend three urban festivals.

Festival Management and Event Tourism, 3(3), 121-128.

Stevens, J.P. (1992). Applied Multivariate Statistics for the Social Sciences. (2 ${ }^{\text {nd }}$ ed.).

Hillsdale, NJ: Erlbaum.

Uysal, M., Gahan, L., \& Martin, B. (1993). An examination of event motivations: A case study. Festival Management and Event Tourism, 1(1), 5-10. 
Table 1: Summary of Research on Festival Motivation

\section{Researcher}

Uysal et al. (1993)

Mohr et al. (1993)

Scott (1996)
Major Objective

Examine dimensions of

event motivations

Identify dimensions of

event motivations;

examine variations of

demographic variables;

delineated factors and

satisfaction by visitor

types

Backman et al. (1995)

Examine dimensions of

event motivation;

analyze variation of

delineated factors and

activities by

demographic variables

Determine differences

among visitors'

motivations to attend

three festivals; examine

motivational

differences between

first time and repeat

visitors excitement; sociability;

family togetherness;

curiosity; escape socialization; family

togetherness

Event Name/ Location

Corn Festival/USA

Balloon Festival/USA

family togetherness;

excitement/uniqueness;

event novelty

Excitement; external;

Pleasure Travel Market

family; socializing;

Survey/USA

relaxation

Nature appreciation; event

Bug Fest/USA 


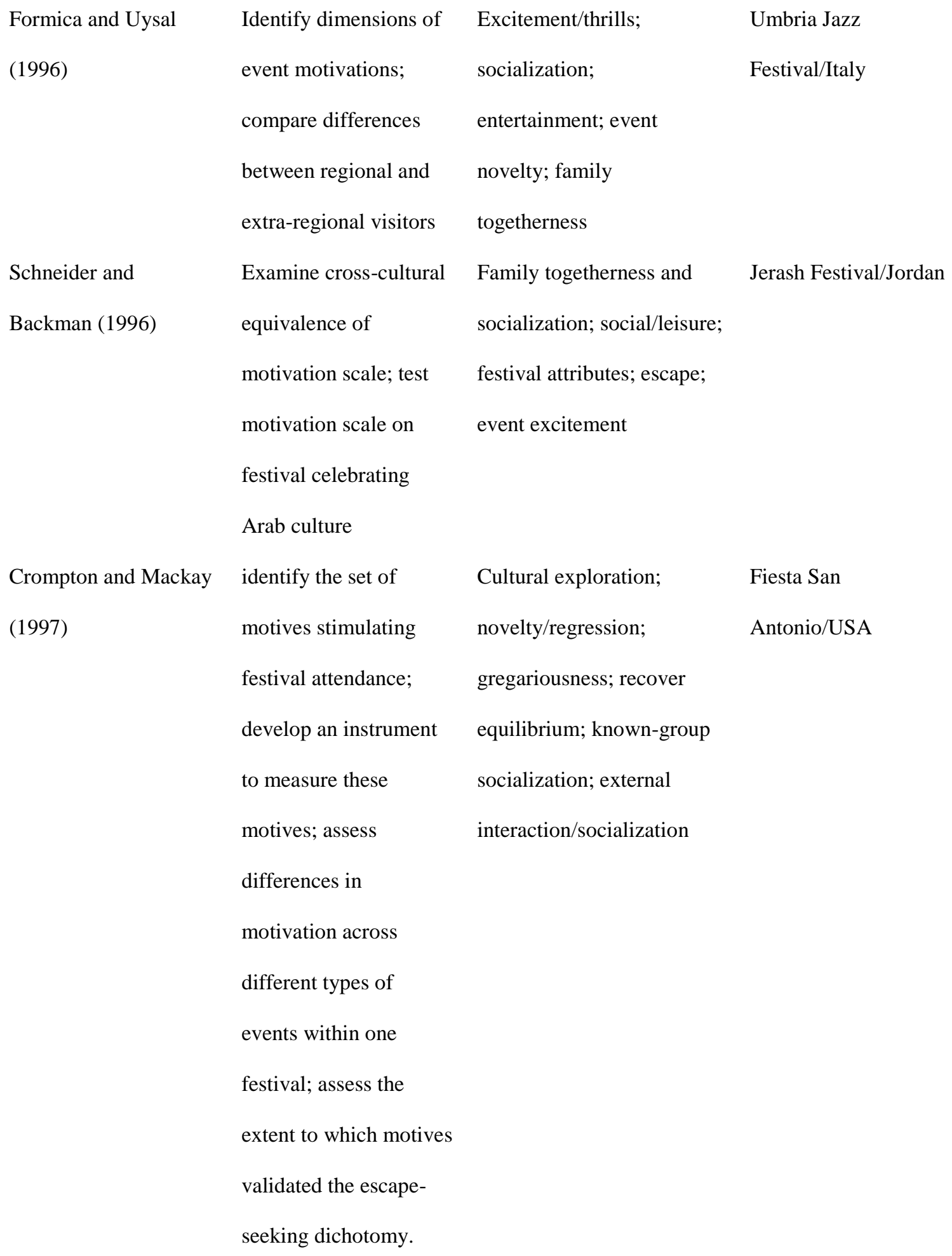




\begin{tabular}{|c|c|c|c|}
\hline Formica and Uysal & Determine principal & Socialization/entertainment; & Spoleto Festival/Italy \\
\hline (1998) & event motivations; & event attraction/excitement; & \\
\hline & cluster festival visitors & group togetherness; site & \\
\hline & based on motivational & novelty; cultural/historical; & \\
\hline & behaviour & family togetherness & \\
\hline Lee $(2000)$ & Identify major driving & Cultural exploration; & 1998 World Culture \\
\hline & motivation factors; & escape; novelty; event & Expo/South Korea \\
\hline & examine motivation & attractions; family & \\
\hline & differences between & togetherness; external & \\
\hline & Caucasian and Asian & group socialization; known- & \\
\hline & visitors & group socialization & \\
\hline Lee et al. (2004) & identify underlying & Cultural exploration; family & 2000 World Culture \\
\hline & dimensions of & togetherness, novelty; & Expo/South Korea \\
\hline & motivations; segment & escape (recover & \\
\hline & festival market on & equilibrium); event & \\
\hline & delineated motivation & attraction; socialization & \\
\hline & factors; & & \\
\hline & explore differences & & \\
\hline & between domestic and & & \\
\hline & foreign visitors on & & \\
\hline & segments; examine & & \\
\hline & importance of & & \\
\hline & motivation & & \\
\hline & clusters and type of & & \\
\hline & visitors as factors & & \\
\hline
\end{tabular}




$\begin{array}{llll}\text { Chang (2005) } & \text { Profile festival } & \text { Equilibrium recovery; } & \text { Wu-tai annual } \\ & \text { attendees on basis of } & \text { festival participation and } & \text { aboriginal } \\ \text { motive and } & \text { learning; novelty seeking; } & \text { festival/Taiwan } \\ & \text { demographic } & \text { socialization; cultural } & \\ \text { characteristics; } & \text { exploration } \\ & \text { development, test and } & \\ & & \\ \text { apply existing scale of } & & \\ & \text { festival motivation } & \end{array}$

Adapted from Lee et al. (2004) 


\section{Table 2: Factor Analysis of Naadam Cultural Festival Visitor Motivation}

Visitor Motivation Variables

1

2

3

Facto

Factor

Communality

Factor 1: Cultural Exploration

I want to experience Mongolian

culture

I wish to learn more about

Mongolian culture

4

5

I would like my family to learn

more about Mongolian culture

I enjoy experiencing culture in its

unique, historical setting

I admire the talents of the sports

competitors

.472

The Naadam festival is exciting

.442
.568

.647

.605

.539

the festival with friends/group

I want to spend leisure time with

my family

I am supporting certain

competitors

I know people who are competing 
I thought my family would enjoy

the Naadam festival

.550

.564

I like to be with people who enjoy

the same things I do

.533

.422

Factor 3: Socialisation

I am an adventure seeker

I like to meet people from all over

the world

I like being with people who are

enjoying themselves

Factor 4: Sports Attraction

I am a keen sports fan

I enjoy the festival atmosphere

I enjoy sports events

I was curious about the Naadam

festival

Factor 5: Local Special Events

I enjoy special events

I thought the Naadam festival

sounded like fun

I like to experience local customs

and cultures

I am interested in local events

I enjoy cultural experiences 
I enjoy the music, ritual and

dance which accompanies the

sporting events

.420

.356

Eigenvalue

7.75

2.945

1.438

$1.193 \quad 1.036$

Variance (\%)

29.832

11.327

5.531

4.590

3.986

Cumulative Variance (\%)

29.832

$41.159 \quad 46.690$

51.280

55.266

Cronbach's Alpha

.82

.79

.64

.72

.77

Number of Items $($ Total $=14)$

6

6

3

4

6

Note: only loadings above .4 are displayed. 
Table 3: ANOVA and Scheffe Multiple Range Tests on Five Motivation Clusters Scheffe test results

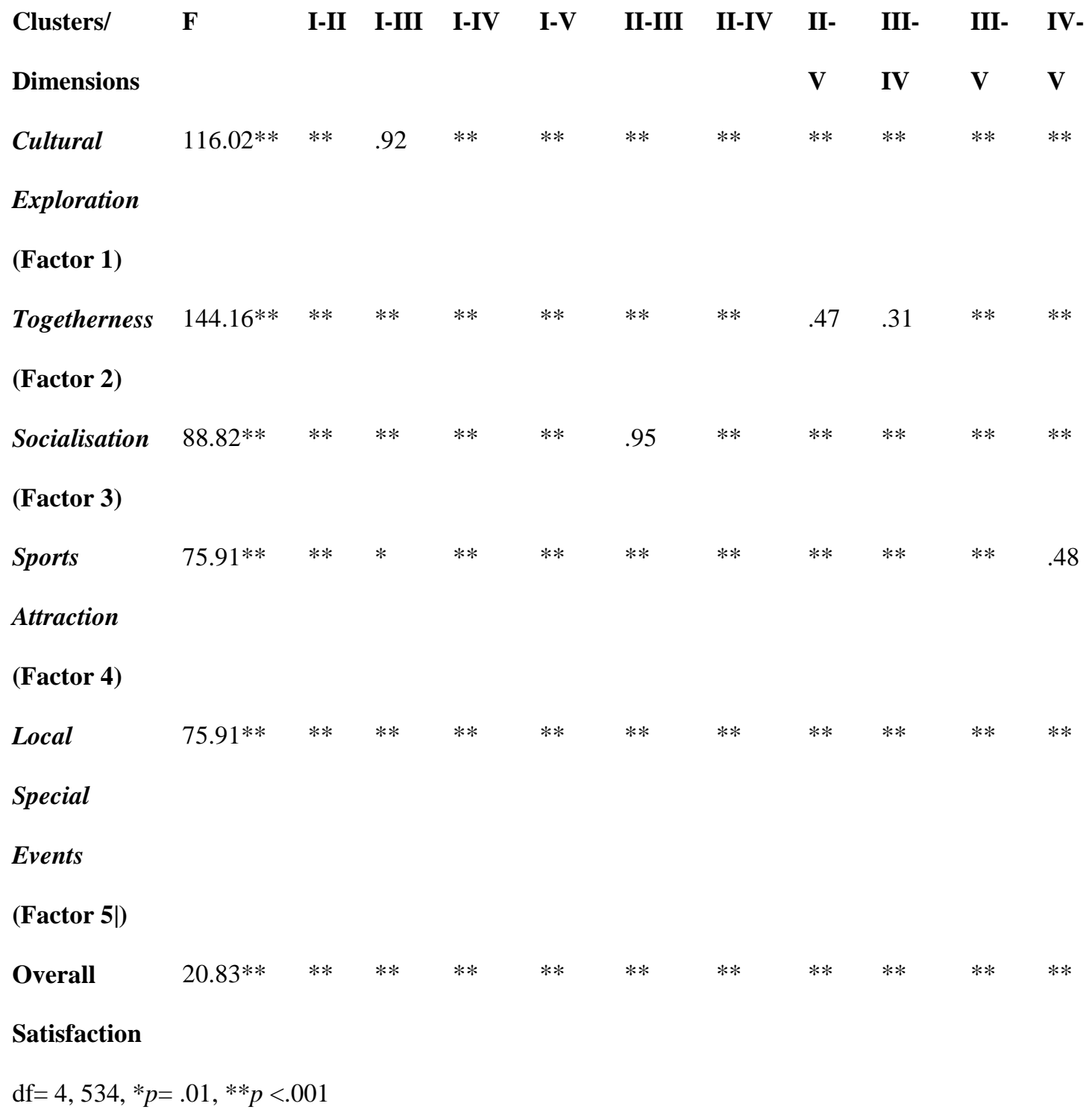




\section{Table 4: Results of K-Means Cluster Analysis for Visitor Motivations}

$\begin{array}{llllll}\text { Clusters/ } & \text { Cluster 1 } & \text { Cluster II } & \text { Cluster III } & \text { Cluster IV } & \text { Cluster V } \\ \text { Dimensions } & (\mathbf{n}=\mathbf{1 5 6}) & (\mathbf{n}=\mathbf{3 8}) & (\mathbf{n}=\mathbf{8 1}) & (\mathbf{n}=\mathbf{1 6 7}) & (\mathbf{n}=\mathbf{9 7}) \\ \text { Cultural } & 6.43 & 3.83 & 6.29 & 5.30 & 5.56 \\ \text { Exploration } & & & & & \end{array}$

(Factor 1)

Togetherness

6.07

3.70

5.81

5.10

3.62

(Factor 2)

Socialisation

5.90

3.59

4.08

4.99

5.95

(Factor 3)

Sports

6.14

3.62

6.02

4.97

4.94

Attraction

(Factor 4)

Local Special

6.21

3.68

5.25

4.83

5.74

Events

(Factor 5|)

Cluster Labe

Multi-

Indifferen

Culture and

Togetherness,

Socialisation

purpose

Sports

Socialisation

\&

Seekers

Seekers

\&Sports

Local Special

Seekers

Event Seekers

Mean values were computed on the basis of aggregated scores for each dimension from attribute ratings on a 7-point Likert scale $(1=$ very strongly disagree, $2=$ strongly agree, $3=$ disagree, $4=$ neither disagree nor agree, $5=$ agree, 6 $=$ strongly agree, 7 = very strongly agree) . 
Table 5: ANOVA and Scheffe Multiple Range Tests on Four Motivation Clusters

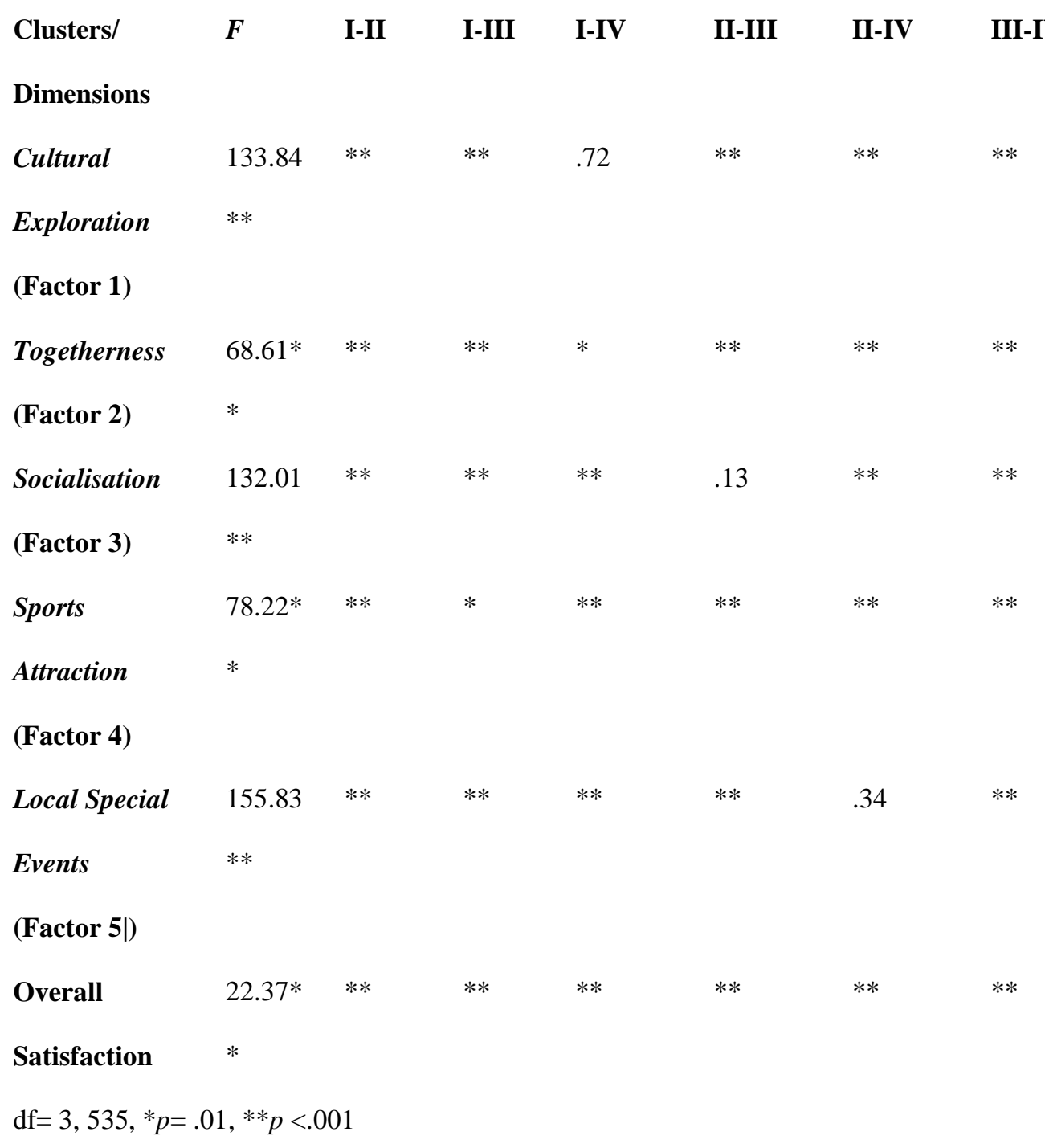




\section{Table 6: Results of K-Means Cluster Analysis for Visitor Motivations}

$\begin{array}{lllll}\text { Clusters/ } & \text { Cluster 1 } & \text { Cluster II } & \text { Cluster III } & \text { Cluster IV } \\ \text { Dimensions } & (\mathbf{n = 1 4 8}) & (\mathbf{n}=\mathbf{1 8 8}) & (\mathbf{n}=\mathbf{6 1}) & (\mathbf{n}=\mathbf{1 4 2}) \\ \text { Cultural } & 6.33 & 5.20 & 4.45 & 6.31 \\ \text { Exploration } & & & & \end{array}$

(Factor 1)

Togetherness $\quad 5.45$

5.45

4.44

4.06

6.08

(Factor 2)

Socialisation

6.19

5.40

3.60

4.61

(Factor 3)

Sports Attraction $\quad 5.84$

4.10

6.09

(Factor 4)

Local Special

6.28

5.10

4.01

5.45

Events

(Factor 5|)

Cluster Label

Multi-purpose
Seekers

Socialisation

Indifferent

Sport \&

Togetherness,

Seekers

Mean values were computed on the basis of aggregated scores for each dimension from attribute ratings on a 7-point Likert scale $(1=$ very strongly disagree, $2=$ strongly agree, 3

= disagree, $4=$ neither disagree nor agree, $5=$ agree, $6=$ strongly agree, $7=$ very strongly agree). 
Table 7: Motivation Cluster Variable Profile

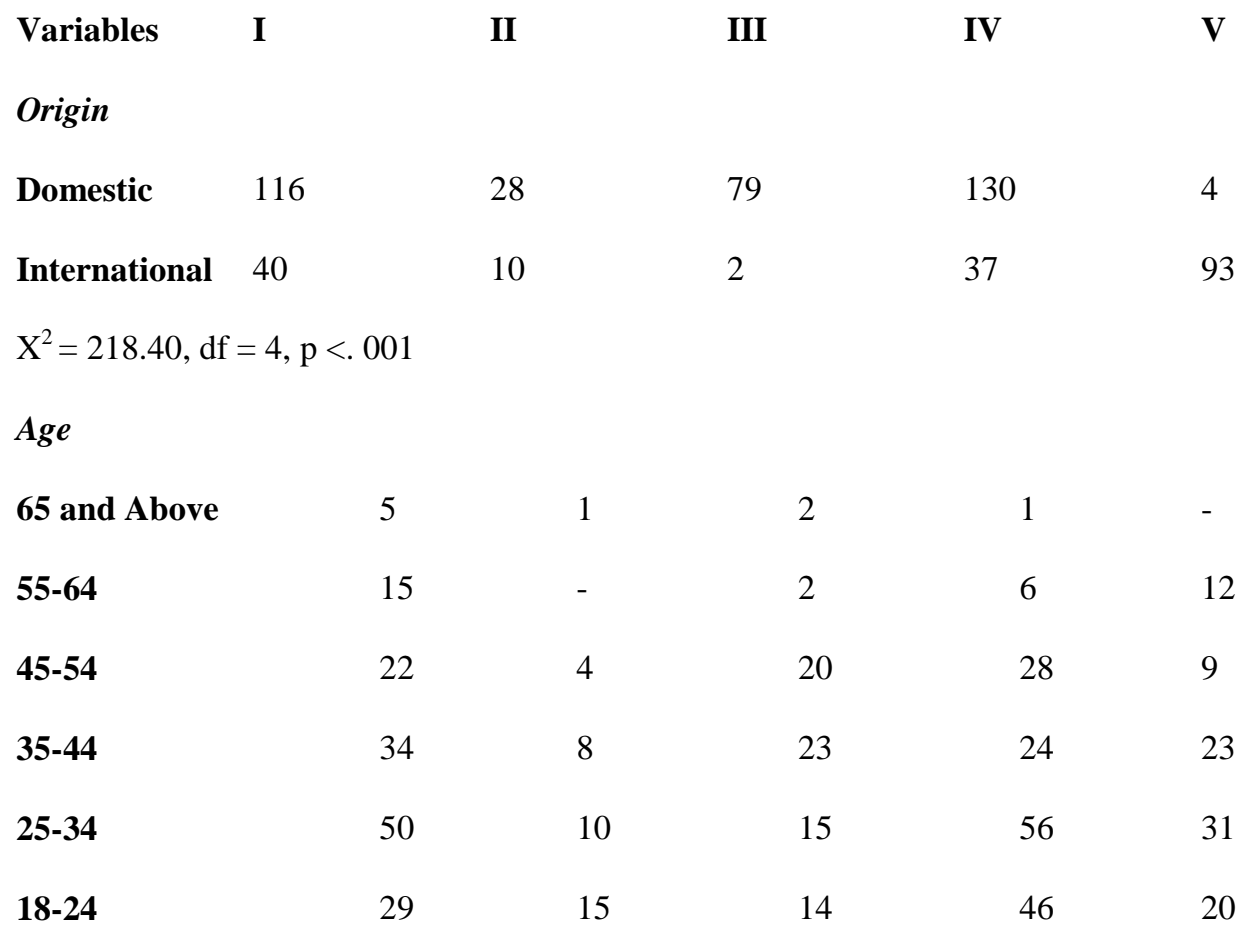

$X^{2}=47.02, \mathrm{df}=20, \mathrm{p}=.001$

Overall Satisfaction

Extremely

37

22

$12 \quad 8$

Satisfactory

Very Satisfactory $\quad 55$

Satisfactory 49

Neither

5

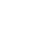

Unsatisfactory

4

9

Very

2

Unsatisfactory

Extremely

1

22

82

32

Unsatisfactory

$X^{2}=112.63, \mathrm{df}=24, \mathrm{p}<.001 *$

$*>20 \%$ of cells have expected count $<5$. 
Table 8: Cluster Variable Profile for Domestic and International Visitors

Variables Domestic (65.9\%)

International (34.1\%)

$\begin{array}{llllllllll}\text { I } & \text { II } & \text { III } & \text { IV } & \text { V } & \text { I } & \text { II } & \text { III } & \text { IV } & \text { V }\end{array}$

Gender

$\begin{array}{lllllllllll}\mathbf{M} & 71 & 15 & 50 & 58 & 3 & 16 & 6 & - & 21 & 47\end{array}$

$\begin{array}{lllllllllll}\text { F } & 41 & 13 & 25 & 67 & 1 & 24 & 3 & 2 & 16 & 43\end{array}$

$X^{2}=11.13, \mathrm{df}=4, p=.03$

$\mathrm{X}^{2}=5.42, \mathrm{df}=4, \mathrm{p}=.25$

Age

65 and $\quad 4$

Above

$\begin{array}{lllllllllll}\mathbf{5 5 - 6 4} & 9 & - & 2 & 2 & - & 6 & - & - & 4 & 12 \\ \mathbf{4 5 - 5 4} & 16 & 2 & 20 & 22 & - & 6 & 2 & - & 6 & 9 \\ \mathbf{3 5 - 4 4} & 29 & 7 & 22 & 19 & 2 & 5 & 1 & 1 & 5 & 21 \\ \mathbf{2 5 - 3 4} & 40 & 7 & 14 & 46 & 1 & 10 & 3 & 1 & 10 & 30 \\ \mathbf{1 8 - 2 4} & 17 & 12 & 14 & 35 & 1 & 12 & 3 & - & 11 & 19\end{array}$

$\mathrm{X}^{2}=42.5, \mathrm{df}=20, \mathrm{p}=.002 . *$

$X^{2}=16.45, \mathrm{df}=20, \mathrm{p}=.69$

Overall

Satisfaction

$\begin{array}{lllllllllll}\text { Extremely } & 26 & - & 21 & 11 & 1 & 11 & - & 1 & 1 & 7\end{array}$

Satisfactory

$\begin{array}{lllllllllll}\text { Very } & 38 & 5 & 26 & 30 & 1 & 17 & 1 & 1 & 5 & 49\end{array}$

Satisfactory

$\begin{array}{llllllllllll}\text { Satisfactory } & 39 & 8 & 22 & 57 & 1 & 10 & 6 & - & 25 & 31\end{array}$

$\begin{array}{llllllllllll}\text { Neither } & 4 & 4 & - & 4 & - & 1 & - & - & 5 & 3\end{array}$

$\begin{array}{lllllllllllll}\text { Unsatisfactory } & 4 & 7 & 5 & 18 & - & - & 2 & - & 0 & 1\end{array}$

Very $\quad-\quad \begin{array}{lllllllll} & 1 & 2 & 4 & - & - & 1 & - & -\end{array}$

Unsatisfactory 


\section{Extremely}

$1-$

\section{Unsatisfactory}

$X^{2}=60.4, d f=24, p<.001 *$

$X^{2}=91.1, d f=24, p<.001 *$

$*>20 \%$ of cells have expected count $<5$. 
Table 9: Two-Way ANOVA on Satisfaction Level by Clusters and Visitor Types

$\begin{array}{llll}\text { df } & \text { Mean } & \text { F } & \text { p } \\ & \text { Square } & & \end{array}$

Main Effects

Five-Clusters Motivation (M)

18.78

16.42

$<.001$

Domestic/International

$1 \quad .53$

.48

.50

Visitors (V)

Interaction Effects

4

.90

.79

.53

$(\mathbf{M} \times \mathbf{V})$

Error

Total

519

Corrected Total 


\section{Table 10: T-Test for Differences in Motivation Cluster Satisfaction by Visitor Type}

$\begin{array}{llllllll}\text { Clusters } & \text { Domestic } & \text { International } & \text { F } & \mathbf{p} & \mathbf{t} & \mathbf{d f} & \mathbf{p} \\ \text { I: Multi-purpose } & 5.66 & 5.97 & 4.63 & .03 & 1.90 & 87.85 & .06\end{array}$

Seekers

II: Indifferent

4.36

4.40

.01

.91

$.08 \quad 33$

.93

III: Culture and

5.68

6.50

.65

.42

$.93 \quad 76$

.35

Sports Seekers

IV:

5.00

4.95

$5.14 \quad .03$

$.29 \quad 78.94$

.77

Togetherness,

Socialisation \&

Sports Seekers

V: Socialisation

6.00

5.64

$.08 \quad .78$

$.85 \quad 92$

.40

\& Local Special

Event Seekers

Overall

5.33

5.51

$13.08<.01$

1.82

$49.39 \quad .06$

Satisfaction

Mean ratings from 7-point Likert scale $(1=$ very strongly disagree, $2=$ strongly agree, $3=$ disagree, $4=$ neither disagree nor agree, 5 = agree, $6=$ strongly agree, $7=$ very strongly agree) 